\title{
Equity portfolio optimization: A DEA based methodology applied to the Zagreb Stock Exchange
}

\author{
Margareta Gardijan ${ }^{1, *}$ and Tihana Škrinjarić ${ }^{1}$ \\ ${ }^{1}$ Faculty of Economics and Business, University of Zagreb, \\ Trg J. F. Kennedyja 6, 10000 Zagreb, Croatia \\ E-mail: 〈\{mgardijan,tskrinjaric\}@efzg.hr $\rangle$
}

\begin{abstract}
Most strategies for selection portfolios focus on utilizing solely market data and implicitly assume that stock markets communicate all relevant information to all market stakeholders, and that these markets cannot be influenced by investor activities. However convenient, this is a limited approach, especially when applied to small and illiquid markets such as the Croatian market, where such assumptions are hardly realistic. Thus, there is a demand for including other sources of data, such as financial reports. Research poses the question of whether financial ratios as criteria for stock selection are of any use to Croatian investors. Financial and market data from selected publicly companies listed on the Croatian capital market are used. A two-stage portfolio selection strategy is applied, where the first stage involves selecting stocks based on the respective Data Envelopment Analysis (DEA) efficiency scores. DEA models are becoming popular in stock portfolio selection given that the methodology includes numerous models that provide a great flexibility in selecting inputs and outputs, which in turn are considered as criteria for portfolio selection. Accordingly, there is much room for improvement of the current proposed strategies for selecting portfolios. In the second stage, two portfolio-weighting strategies are applied using equal proportions and scoreweighting. To show whether these strategies create outstanding out-of-sample portfolios in time, time-dependent DEA Window Analysis is applied using a reference time of one year, and portfolio returns are compared with the market portfolio for each period. It is found that the financial data are a significant indicator of the future performance of a stock and a DEA-based portfolio strategy outperforms market return.
\end{abstract}

Key words: portfolio selection, optimization, DEA, financial ratios, window analysis, stock market dynamics

Received: September 10, 2014; accepted: October 7, 2015; available online: October 31, 2015

DOI: $10.17535 /$ crorr.2015.0031

\section{Introduction}

The analysis of stocks and portfolio risk management have been in the attention of investors and academics for decades. Throughout the years, a great number of models, methods and techniques have been introduced for solving different

${ }^{*}$ Corresponding author. 
practical problems. One of those problems, which happens to be the main concern for (potential) investors, is how to structure a stock portfolio. One of the reasons why structuring a portfolio presents a problem is the fact that much relevant data has to be considered when making an important investing decision. In order to form a portfolio, investors usually look at numerous data from the market and from financial reports, and calculate certain measures in order to compare different stocks. According to many studies, financial ratios from data in company financial reports have proven to be useful in portfolios management as they provide meaningful information on companies, thus assisting investment decisions (Chen and Shimerda 1981, Singh and Schmidgall 2002). However, the drawbacks of this approach are that financial statements can provide unreliable information due to accounting practices or fraud attempts, while collecting data from financial reports is time consuming for investors. On the other hand, market data collected from stock exchanges, such as data on prices, volume, liquidity as well as ratios produced from such data analysis, are valuable information. Although market data should reflect a stock issuer's overall health, market data can be greatly influenced by investors' perceptions of the market and their behavior. Yet, most strategies for selecting portfolios are concentrated solely on market data under the assumption that the stock market is efficient, that it reflects all relevant information to all market stakeholders and that it cannot be influenced by investor activities. This paper assesses whether combining these two sources of data is of value to investors in making better investment decisions, especially in a small, shallow and relatively illiquid market, such as the Croatian market, where market data can be more easily manipulated through market perceptions and trading activities of market stakeholders.

However, processing a vast amount of data and comparing alternatives using a number of criteria is not an easy task. That is why using mathematical programming and computational solving of the portfolio selection programs greatly assists in handling vast amount of data and investing goals, and without which the problem could not be solved as fast and as efficiently (if the solution exists). When the number of criteria for portfolio selection is considered, it is convenient to perform a DEA analysis. Data Envelopment Analysis (DEA) is a relatively new area of operations research, used in evaluating the relative efficiency of units within different sets, like companies, hospitals, hotels, countries, investment funds and stocks, production programs, etc. Numerous models have been developed using this methodology and are used to measure and compare the relative efficiency of different assessment units, which do not have to be just production units (Cooper, Seiford and Zhu [3]).

Numerous papers apply DEA in order to select portfolios on foreign stock markets. Since the year 2000, DEA models have been introduced as a tool for evaluating stocks and financial assets. Lopes et al. [8] apply DEA to stocks on the Brazilian stock market and produce portfolios that dominate market 
portfolios in terms of return and risk. Chen [2] analyzed the "size effect" on the Taiwan stock market and constructed small cap and large cap portfolios. Pätäri et al [15] and Powers and McMullen [16] use DEA to identify portfolios that can beat the market. Lim et al [7] use cross-efficiency ratios calculated from financial data of publicly listed Korean companies for selecting portfolios and attain portfolios with higher risk-adjusted returns than other benchmark portfolios for a 9-year sample period from 2002 to 2011. Edirisinghe and Zhang [4] have developed a generalized DEA to determine a relative strength index as an indicator of stock performance that is in turn used as a guide for portfolio management. Song [20] has also investigated the possibility of predicting company performance (and investment opportunity) with a company's operational efficiency score that represents a consolidated measure of financial ratios. Zamani et al [22] have investigated a super-efficiency model on combined market and financial data in order to find an optimal stock portfolio for investors in the Mumbai stock exchange.

Gardijan and Kojić [5] have been the first to apply the DEA-based portfolio selection on the Croatian stock market, and used return and risk measures to identify efficient stocks for a DEA-portfolio. Their strategy beats the markets in about 50 percent of cases. Most of the above-mentioned papers have developed portfolio selection strategies based on DEA scores, resulting in portfolios that have remained dominant over the official stock market index. They have all used BCC (Banker-Charnes -Cooper) and/or CCR (Charnes-Cooper-Rhodes) models, as these have proven to be the most basic ones, but applicable to solving this complex problem. Škrinjarić [19] has applied a Dynamic SlacksBased Measure as a method of forming a portfolio that would predominantly outperform the market, and the results suggest that this approach is superior to basic DEA models. However, despite the characteristics of the Croatian stock market, none of the domestic papers has used, up until now, financial data in DEA models. This paper is structured as follows. In Chapter 2, BCC and CCR models are introduced, which are the basic models of DEA. Chapter 3 presents the portfolio selection methodology that has been used and Chapter 4 explains all the research results.. Finally, conclusions and recommendations for future researches are given in Chapter 5.

\section{DEA methodology background}

Data envelopment analysis (DEA) consists of methods and models which belong to the field of mathematical programming. The purpose is to evaluate the relative efficiency of the decision making units $(D M U)$. Each $D M U$ uses one or more inputs to produce one or more outputs and information on them is used to rank $D M U s$ by their relative efficiency scores. The two most famous models are 
the CCR (Charnes-Cooper-Rhodes, 1987) and BCC (Banker-Charnes-Cooper, 1984) model. The main difference between the two popular models is whether we assume constant (CCR) or variable returns (BCC) to scale. Since they are very popular, we will provide only a brief overview of them. Let us assume we are dealing with data on $m$ inputs $\left(x_{1 j}, x_{2 j}, \ldots, x_{m j}\right)$ and $s$ outputs $\left(y_{1 j}, y_{2 j}, \ldots, y_{s j}\right)$ for each $D M U_{j}, j \in\{1,2, \ldots, n\}$. We can arrange data for $n D M U$ s with $m$ inputs and $s$ outputs in a matrix form as:

$$
\boldsymbol{X}=\left[\begin{array}{cccc}
x_{11} & x_{12} & \ldots & x_{1 n} \\
x_{21} & x_{22} & \ldots & x_{2 n} \\
\ldots & \ldots & \ldots & \ldots \\
x_{m 1} & x_{m 2} & \ldots & x_{m n}
\end{array}\right] \text { and } \boldsymbol{Y}=\left[\begin{array}{cccc}
y_{11} & y_{12} & \ldots & y_{1 n} \\
y_{21} & y_{22} & \ldots & y_{2 n} \\
\ldots & \ldots & \ldots & \ldots \\
y_{s 1} & y_{s 2} & \ldots & y_{s n}
\end{array}\right] \text {, }
$$

where each column $x_{o}=\left(x_{10}, x_{20}, \ldots, x_{m o}\right)^{T}$ is a vector of all the input values and $y_{o}=\left(y_{10}, y_{20}, \ldots, y_{s o}\right)^{T}$ is a vector of all the output values of the $j$-th $D M U$. It is assumed that $\boldsymbol{x}_{0} \geq \mathbf{0}, \boldsymbol{x}_{0} \neq \mathbf{0}$ and $\boldsymbol{y}_{0} \geq \mathbf{0}, \boldsymbol{y}_{0} \neq \mathbf{0}$. In order to evaluate the relative efficiency of each $D M U$, the input- or output-oriented model can be used. The input-oriented model is used when the goal is to minimize inputs under the constraint of minimal output level we want to achieve. Contrary to the mentioned model, the output-oriented model aims to maximize outputs under the constraint of not exceeding a given level of inputs. Since this paper deals with stock return data, it remains unclear as to whether an input- or output-oriented model should be used or whether we should assume constant or variable returns to scale. Thus, all of the mentioned models will be described. The CCR model is based on the assumption of constant returns to scale. The matrix form of the input-oriented CCR model (CCR-I) in the first phase is given in an envelope form as ${ }^{\dagger}$ :

$$
\begin{array}{ll} 
& \min _{\boldsymbol{\lambda}, \theta} \theta \\
\text { subject to } & \\
& \theta \boldsymbol{x}_{\boldsymbol{o}}-\boldsymbol{X} \boldsymbol{\lambda} \geq \mathbf{0} \\
& \boldsymbol{Y} \boldsymbol{\lambda} \geq \boldsymbol{y}_{\boldsymbol{o}} \\
\boldsymbol{\lambda} \geq \mathbf{0}
\end{array}
$$

where $\lambda=\left(\lambda_{1}, \lambda_{2}, \ldots, \lambda_{n}\right)^{T}$ represents a vector of nonnegative constants. The goal is to find the minimal value of $\theta$, which radially reduces the input vector $\boldsymbol{x}_{o}$ towards the value $\theta \boldsymbol{x}_{o}$. The constraints in the model mean that the $D M U$ must remain in the production possibility set and it needs to retain the level of outputs at least equal to the level $y_{o}$. The last constraint is needed due to the

\footnotetext{
${ }^{\dagger}$ It can be written in a multiplicative form also.
} 
second one, because of the assumptions $y_{0} \geq \mathbf{0}$ and $\boldsymbol{y}_{0} \neq \mathbf{0}$. The optimal solution (efficiency score) $\theta^{*}$ is in the interval $(0,1)$ and is interpreted as the rate of input reduction.

In the second phase of the model, the goal is to maximize the sum of input surpluses and output shortfalls of a $D M U_{o}$, where we use the optimal value of $\theta^{*}$ from the first phase. Also, we use the constraint that the $D M U$ must stay in the production possibility set:

$$
\max _{\lambda, s^{-}, \mathbf{s}^{+}} w=\boldsymbol{e s}^{-}+\boldsymbol{e s}^{+}
$$

subject to

$$
\begin{aligned}
& \theta^{*} x-X \lambda=s^{-} \\
& Y \lambda-y=s^{+} \\
& \lambda \geq 0, s^{-} \geq 0, s^{+} \geq 0
\end{aligned}
$$

where $s^{-}=\left(s_{1}{ }^{-}, s_{2}{ }^{-}, \ldots, s_{m}{ }^{-}\right)^{T}$ and $s^{+}=\left(s_{1}{ }^{+}, s_{2}{ }^{+}, \ldots, s_{r}{ }^{+}\right)^{T}$ are vectors of input excesses and output shortfalls, respectively, and $\boldsymbol{e}=(1,1, \ldots, 1)$. The optimal solution of $(3)\left(\lambda^{*}, s^{-^{*}}, s^{+^{*}}\right)$ is called the max-slack solution. $D M U_{o}$ is CCR efficient if the optimal solution of both phases $\left(\theta^{*}, \lambda^{*}, s^{-*}, s^{+*}\right)$ satisfies the following conditions: $\theta^{*}=1, \boldsymbol{s}^{\mathbf{}^{*}}=\mathbf{0}$ and $\boldsymbol{s}^{+^{*}}=\mathbf{0}$.

If $D M U s$ are output oriented, we form the following output oriented CCR model (CCR-O). In the first phase, the goal is to maximize $\eta$ (rate of output increase):

$$
\max _{\mu, \eta} \eta
$$

subject to

$$
\begin{aligned}
& x_{o}-X \mu \geq 0 \\
& \eta y_{o}-Y \mu \leq 0 \\
& \mu \geq 0
\end{aligned}
$$

where $\boldsymbol{\mu}=\left(\mu_{1}, \mu_{2}, \ldots, \mu_{n}\right)^{T}$ is a vector of nonnegative constants. The optimal value is $\eta^{*} \geq 1$. The greater the optimal value is, the more inefficient the $D M U$ is. In the second phase, we maximize the sum of input surpluses and output shortfalls of a $D M U_{o}$ again

$$
\max _{\mu, \mathbf{t}^{-}, \mathbf{t}^{+}} \omega=\boldsymbol{e t}^{-}+\boldsymbol{e} \boldsymbol{t}^{+}
$$

subject to

$$
\begin{aligned}
& x_{o}-X \boldsymbol{\mu}=\boldsymbol{t}^{-} \\
& \eta^{*} y_{o}-\boldsymbol{Y} \boldsymbol{\mu}=\boldsymbol{t}^{+} \\
& \boldsymbol{\mu} \geq \mathbf{0}, \boldsymbol{t}^{-} \geq \mathbf{0}, \boldsymbol{t}^{+} \geq \mathbf{0}
\end{aligned}
$$

where $\boldsymbol{t}^{-}=\left(t_{1}^{-}, t_{2}^{-}, \ldots, t_{m}{ }^{-}\right)^{T}$ is the vector of input surpluses, $\boldsymbol{t}^{+}=\left(t_{1}^{+}, t_{2}^{+}, \ldots, t_{r}^{+}\right)^{T}$ is the vector of output shortfalls, and $\eta^{*}$ is obtained from the first phase. The 
relationship between optimal values of input and output oriented models can be seen in Cooper, Seiford and Zhu [3].

The BCC model is used when variable returns to scale are assumed. The only difference between BCC and the previous CCR models (2-5) is that in each phase of the optimization we need to include the convexity constraint. In the input-oriented model, we include the constraint:

$$
\sum_{j=1}^{n} \lambda_{j}=1
$$

i.e., in the output-oriented model we include:

$$
\sum_{j=1}^{n} \mu_{j}=1
$$

The BCC and CCR are both static models. However, efficiency changes over time and using dynamic concepts is far more useful on stock markets. Therefore, it is useful to apply Window Analysis (Klopp [6]), which can be applied for each of the mentioned models. The Window Analysis is based on dividing the whole period of analysis into $k$ moving average time-windows of length $p$, and obtaining the efficiency scores for $k \cdot p D M U s$ by solving the aforementioned optimization problems (2-7) for each window. In that way, each $D M U$ is analyzed and compared not only to other $D M U s$, but also to itself in different periods. Furthermore, under the assumption that the technology does not change in the observed period, one can observe efficiency changes of each $D M U$ over time and make timely decisions, which can improve business results, etc. An important feature of the Window Analysis is that it increases the number of units for evaluation, consequently increasing the discriminatory power of the method (Cooper, Seiford, Tone, [2007]).

\section{Methodology for DEA portfolio selection}

The sample contains data on stocks that were listed on Zagreb stock exchange from January 2007 to June 2014. Given that the Croatian stock market is developing and is relatively small and illiquid, the initial sample consists of 41 stock which were traded on at least half of the total trading days within the observed period. The main idea of the portfolio selection strategy is to form a stock portfolio based on both financial and market data as selection criteria. Quarterly data and quarters were utilized as reference periods for adjusting strategies because listed companies publish financial reports on a quarterly basis.

Quarterly returns, Jensen's and Sharpe ratio, as well as standard deviation, expected shortfall and Beta coefficient as risk measures were all calculated using 
daily average prices ${ }^{\ddagger}$. Quarterly return $R_{i k}$ for $i$-th stock in $k$-th quarter, $i \in\{1,2, \ldots, 41\}, k \in\{1,2, \ldots, 25\}$ is calculated as:

$$
\begin{gathered}
R_{i k}=\frac{\sum_{j=1}^{n_{k}} r_{j}^{i k}}{n_{k}}, \\
r_{j}^{i k}=\ln \frac{P_{j}^{i k}}{P_{j-1}^{i k}}, j \in\left\{1, \ldots, n_{k}\right\},
\end{gathered}
$$

where $r_{j}^{i k}$ is the $j$-th daily return and $P_{j}^{i k}$ the $j$-th observation of an average daily price of the $i$-th stock in the $k$-th quarter, and $n_{k}$ is a number of trading days in the $k$-th quarter. Jensen's alpha in the $k$-th quarter for the $i$-th stock was calculated using formula:

$$
\alpha_{i k}=R_{i k}-R_{f, k}-\beta_{i k}\left(R_{M, k}-R_{f, k}\right),
$$

where $R_{f, k}$ is a risk-free interest rate and $R_{M, k}$ is a market return in the $k$-th quarter, and $\beta_{i k}$ is a beta coefficient for the $i$-th stock in the $k$-th quarter:

$$
\beta_{i k}=\frac{\operatorname{Cov}\left(r_{j}^{i k}, r_{j}^{M k}\right)}{\sigma_{M, k}}, j \in\left\{1, \ldots, n_{k}\right\} .
$$

Sharpe's ratio $(S R)$ for the $i$-th stock in the $k$-th quarter is calculated using the formula:

$$
S R_{i k}=\frac{R_{i k}-R_{f, k}}{\sigma_{i k}},
$$

where $\sigma_{i k}$ is a standard deviation of $i$-th stock in the $k$-th quarter calculated as:

$$
\sigma_{i k}=\sqrt{\frac{\sum_{j=1}^{n_{k}}\left(r_{j}^{i k}-R_{i k}\right)^{2}}{n_{k}} .}
$$

Expected Shortfall $(E S)$, a coherent risk measure ${ }^{\S}$ from the family of $V a R$ risk models, which is considered to be a more appropriate risk measure then the "ordinary" $\mathrm{VaR}$, at $\alpha=5 \%$, which is calculated from a daily return distribution as:

$$
\begin{gathered}
E S_{0.95}^{i k}=E\left[r_{j}^{i k}: r_{j}^{i k}<\operatorname{VaR} R_{0.95}^{i k}\right]=\frac{\sum_{j} r_{j}^{i k}}{k(S)}, j \in S=\left\{r_{j}^{i k}: r_{j}^{i k}<V a R_{0.95}^{i k}\right\}, \\
\operatorname{VaR} R_{0.95}^{i k}=\max \left\{r_{j}^{i k}: F_{i k}\left(r_{j}^{i k}\right) \leq 0.05\right\},
\end{gathered}
$$

\footnotetext{
The missing values of the daily average price for some stocks are replaced with the average of previous and next available prices in the dataset of daily average prices.

$\S$ More on coherent risk measures in Artzner et al (1999) Coherent measures of risk. Mathematical Finance, Vol. 9, No. 3 (July 1999), 203-228.
} 
where $k(S)$ is a number of members in $S, F_{i k}\left(r^{i k}\right)$, which is a cumulative distribution of return for the $i$-th stock in the $k$-th quarter.

Žager et al [23:243-254] state that a company can be evaluated and compared to others from six important perspectives: liquidity, profitability, debt, activity (operating performance), investability and efficiency using specific financial ratios. The ratios they highlight as important for evaluating each aspect are: current ratio (CR) for liquidity, return on assets (ROA) and return on equity (ROE) for profitability, debt ratio (DR) and debt-to-equity ratio (DTE) for debt, asset turnover for activity, total share rentability (TSR) for investability and expense ratio (ER) for efficiency. Following their approach, we calculate the ratios from the financial reports and market data. Ratios and measures that indicate good performance (returns, Jensen's alpha, Sharpe ratios, ROA, ROE, ER, TSR and CR) should be as large as possible and for the other ones (SD, ES, Beta (absolute), DR, DTE) should be as small as possible, so we treat the "desirable" ratios as outputs for DEA and "undesirable" ones as inputs. The preferred value of the turnover ratio depends on the industry in which a company is operating, so this ratio was omitted from the analysis since it is not comparable among given stock issuers. Average correlations of variables for the whole period (given the correlations within one window) are given in Table 1.

\begin{tabular}{|c|c|c|c|c|c|c|c|c|c|c|c|c|c|}
\hline & SD & ES & Beta & DR & DTE & Returns & Sharpe & Jensen & CR & ROA & ROE & ER & TSR \\
\hline S & 1 & 0,902 & 0,610 & 0,817 & $-0,177$ & 0,312 & 0,694 & 0,312 & $-0,278$ & 0,779 & 0,174 & 0,772 & 0,132 \\
\hline ES & 0,902 & 1 & $-0,594$ & $-0,660$ & 0,187 & 0,052 & $-0,656$ & 0,051 & 0,304 & $-0,590$ & $-0,188$ & $-0,588$ & $-0,096$ \\
\hline Beta & 0,610 & $-0,594$ & 1 & 0,471 & 0,118 & 0,110 & 0,426 & 0,112 & $-0,080$ & 0,433 & $-0,218$ & 0,481 & 0,131 \\
\hline DR & 0,817 & $-0,660$ & 0,471 & 1 & $-0,041$ & 0,323 & 0,300 & 0,323 & $-0,271$ & 0,918 & $-0,025$ & 0,966 & 0,294 \\
\hline DTE & $-0,177$ & 0,187 & 0,118 & $-0,041$ & 1 & $-0,130$ & $-0,119$ & $-0,129$ & 0,021 & $-0,006$ & $-0,907$ & $-0,014$ & 0,092 \\
\hline Returns & 0,312 & 0,052 & 0,110 & 0,323 & $-0,130$ & 1 & 0,213 & 1,000 & 0,135 & 0,423 & 0,077 & 0,423 & $-0,019$ \\
\hline Sharpe & 0,694 & $-0,656$ & 0,426 & 0,300 & $-0,119$ & 0,213 & 1 & 0,213 & $-0,201$ & 0,253 & 0,163 & 0,243 & $-0,115$ \\
\hline Jensen & 0,312 & 0,051 & 0,112 & 0,323 & $-0,129$ & 1,000 & 0,213 & 1 & 0,135 & 0,423 & 0,077 & 0,424 & $-0,019$ \\
\hline CR & $-0,278$ & 0,304 & $-0,080$ & $-0,271$ & 0,021 & 0,135 & $-0,201$ & 0,135 & 1 & $-0,077$ & $-0,023$ & $-0,114$ & $-0,095$ \\
\hline ROA & 0,779 & $-0,590$ & 0,433 & 0,918 & $-0,006$ & 0,423 & 0,253 & 0,423 & $-0,077$ & 1 & 0,009 & 0,952 & 0,344 \\
\hline ROE & 0,174 & $-0,188$ & $-0,218$ & $-0,025$ & $-0,907$ & 0,077 & 0,163 & 0,077 & $-0,023$ & 0,009 & 1 & $-0,084$ & $-0,065$ \\
\hline ER & 0,772 & $-0,588$ & 0,481 & 0,966 & $-0,014$ & 0,423 & 0,243 & 0,424 & $-0,114$ & 0,952 & $-0,084$ & 1 & 0,294 \\
\hline TSR & 0,132 & $-0,096$ & 0,131 & 0,294 & 0,092 & $-0,019$ & $-0,115$ & $-0,019$ & $-0,095$ & 0,344 & $-0,065$ & 0,294 & 1 \\
\hline
\end{tabular}

Table 1: Correlation matrix of the used variables

The idea behind the analysis is to calculate the efficiency scores for each stock in each window given the values of market and financial ratios and measures according to which we will structure our stock portfolios. Using quarterly data from October 2007 until January 2014, quarterly efficiency scores were obtained from CCR-I, CCR-O, BCC-I and BCC-O models for each stock in each quarter. Out-of-sample portfolios are constructed at the beginning of October 2008, given the average efficiency scores from the quarterly in-sample 
data regarding the previous 4 quarters (October 2007 - September 2008). Portfolios are then restructured every 4 quarters given the stocks' average efficiency scores in 4 previous quarters (the previous out-of-sample period becomes a new in-sample period for estimation of efficiency). For 6 periods of investment, the assumption is that a portfolio is restructured on the first trading day of each October from 2008-2013, no transactions are made in between, there are no transaction costs and short selling is not allowed. The total number of evaluated $D M U_{\mathrm{s}}$ in the Window Analysis is $k \cdot n=7 \cdot 41=287$, what is obviously greater than the $3 \cdot$ (number of inputs $(m)+$ number of outputs $(s))=39$, which is in accordance with recommendations for the stability of the model.

Since the models can evaluate that none of the stocks is fully efficient, given the data of a certain period, the decision was made to test the portfolio selection strategy by selecting all stocks that have an average efficiency score in the top $10 \%$ in a certain period (further "10\% selection strategy"). In addition, two different portfolio weighting strategies were applied: using equal proportions and using 'efficiency score - weighting' (share of stock's efficiency to total efficiency of stocks contained in portfolio). Using the attained scores and mentioned strategies, we formed strategies for 8 portfolios for each year from 2008-2013. For denoting portfolios, we use following symbols: $I$-input oriented, $O$ - output oriented, $C-$ constant returns to scale, $V-$ variable returns to scale, 10 - formed by a " $10 \%$ selection strategy", eq - equally weighted, wweighted by efficiency scores, so we have portfolios: IC10eq, IC10w, IV10eq, IV10w, OC10eq, OC10w, OV10eq and OV10w.

For each investment period (4 quarters), we calculated the achieved return and compared it to out-of-sample market return. The obtained results and analysis are given in the following section.

\section{Results of the empirical analysis}

The out-of-sample market and portfolio returns are given in Table 2 .

\begin{tabular}{|c|c|c|c|c|c|c|c|c|c|}
\hline Period & crobex & oc10eq & oc10w & ov10eq & ov10w & $i c 10 e q$ & $i c 10 w$ & $i v 10 e q$ & $i v 10 w$ \\
\hline 4Q08-3Q09 & -0.161 & -0.119 & -0.121 & -0.127 & -0.128 & -0.119 & -0.121 & -0.169 & -0.169 \\
\hline 4Q09-3Q10 & -0.061 & 0.000 & 0.007 & 0.000 & 0.006 & 0.0005 & 0.007 & 0.041 & 0.041 \\
\hline 4Q10-3Q11 & -0.018 & -0.079 & -0.077 & -0.067 & -0.067 & -0.079 & -0.077 & -0.067 & -0.067 \\
\hline 4Q11-3Q12 & -0.036 & -0.005 & -0.019 & -0.014 & -0.013 & -0.005 & -0.005 & -0.005 & -0.005 \\
\hline 4Q12-3Q13 & 0.020 & 0.032 & 0.032 & 0.076 & 0.076 & 0.010 & 0.010 & 0.065 & 0.065 \\
\hline 4Q13-2Q14 & -0.004 & 0.217 & 0.219 & 0.217 & 0.217 & 0.217 & 0.219 & 0.122 & 0.122 \\
\hline 4Q08-2Q14 & $\mathbf{- 0 . 2 6 0}$ & $\mathbf{0 . 0 4 6}$ & $\mathbf{0 . 0 4 1}$ & $\mathbf{0 . 0 8 6}$ & $\mathbf{0 . 0 9 1}$ & $\mathbf{0 . 0 2 4}$ & $\mathbf{0 . 0 3 4}$ & $\mathbf{- 0 . 0 1 2}$ & $\mathbf{- 0 . 0 1 2}$ \\
\hline
\end{tabular}

Table 2: The returns of the DEA-portfolios (in \%)

The returns of the DEA-portfolios are in general greater than the market return (shaded cells in Table 2). Precisely, the returns from the DEA-portfolios 
are greater in $83 \%$ of periods for all models. The market portfolio is strictly more successful than the DEA-portfolios in one investment period (October 2010-September 2011). Moreover, all DEA portfolios have a greater cumulative return than the market. As expected, the efficiency-weighted portfolios are at the same time overall more successful than the equally weighted portfolios, confirming that efficiency scores can serve as a good guidance for determining portfolio weights. In cases when utilized DEA models evaluate a great number of stocks as efficient but portfolio selection is constrained by a number of stocks or budget, super-efficiency DEA models can be used in order to weight portfolios.

The greatest return was accomplished with the ov10w portfolio, followed by ov10eq, oc10eq and oc10w portfolio (Figure 1). If we additionally compare the results from portfolios, the conclusion is that scores from the output-oriented models gave more aggressive portfolios, as expected. This is so because these models maximize the output at a given level of input, whereas the inputoriented models produced a more conservative portfolio by minimizing inputs for a given level of outputs.

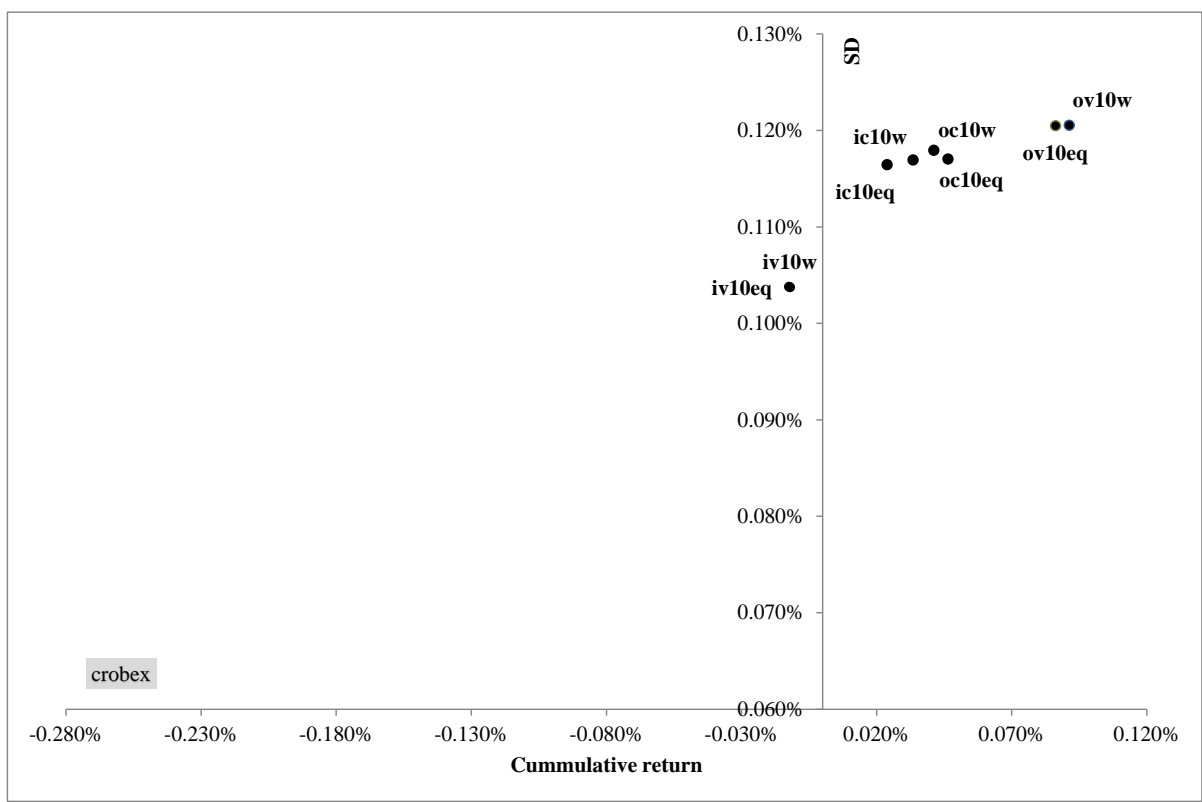

Figure 1: Cumulative returns and risk performance of the analyzed portfolios

To determine whether including financial ratios contributes to the successfulness of the DEA portfolio selection strategy, a DEA analysis was made with the same sample of stocks using just the market data, and the efficiency scores for stocks from 4 mentioned models were obtained. Those scores were also 
used to form the stock portfolios, and the same strategies were used. Their returns are given in Table 3 .

\begin{tabular}{|c|c|c|c|c|c|c|c|c|c|}
\hline Period & crobex & oc10eq- & oc10w- & ov10eq- & ov10w- & $i c 10 e q-$ & $i c 10 w-$ & $i v 10 e q-$ & $i v 10 w-$ \\
\hline 4Q08-3Q09 & -0.161 & -0.183 & -0.183 & -0.178 & -0.179 & -0.183 & -0.183 & -0.105 & -0.104 \\
\hline 4Q09-3Q10 & -0.061 & -0.029 & -0.035 & -0.041 & -0.039 & -0.029 & -0.035 & -0.052 & -0.054 \\
\hline 4Q10-3Q11 & -0.018 & -0.104 & -0.095 & -0.075 & -0.070 & -0.104 & -0.095 & -0.030 & -0.039 \\
\hline 4Q11-3Q12 & -0.036 & -0.014 & -0.014 & -0.056 & -0.043 & -0.014 & -0.014 & 0.008 & 0.011 \\
\hline 4Q12-3Q13 & 0.020 & 0.070 & 0.063 & 0.091 & 0.086 & 0.070 & 0.071 & 0.090 & 0.088 \\
\hline 4Q13-2Q14 & -0.004 & 0.199 & 0.202 & 0.119 & 0.118 & 0.199 & 0.202 & 0.091 & 0.090 \\
\hline 4Q08-2Q14 & $\mathbf{- 0 . 2 6 0}$ & $\mathbf{- 0 . 0 6 1}$ & $\mathbf{- 0 . 0 6 2}$ & $\mathbf{- 0 . 1 4 1}$ & $\mathbf{- 0 . 1 2 8}$ & $\mathbf{- 0 . 0 6 1}$ & $\mathbf{- 0 . 0 5 4}$ & $\mathbf{0 . 0 0 2}$ & $\mathbf{- 0 . 0 0 8}$ \\
\hline
\end{tabular}

Table 3: The returns of the O-portfolios $\underset{\%}{\text { and }}$. I-portfolios, without financial ratios (in

Obviously, portfolio iv10eq- dominates the market portfolio and other portfolios. However, its overall return is significantly smaller than the highest return obtained from models accounting for financial ratios. We can conclude that including financial ratios in the portfolio selection does influence the successfulness of portfolios using this methodology. This additionally demonstrates that incorporating other measures besides stock return and risk can enhance a portfolio results.

\section{Conclusions}

There are many approaches and methodologies that tend to solve the portfolio selection problem, but many methodologies use only market data. However, market data is not always a realistic reflection of the financial situation and overall business health of the stock issuer, since market data is influenced by the behavior of market stakeholders whose transactions and moves at certain periods cannot be explained as rational. Although there is always the risk that financial data published in financial reports that listed companies are obligated to publish could be "enhanced" by accounting policies and practice, it is a useful additional insight in the company's financial situation and future perspective. However, additional information that has to be incorporated in models complicates the analysis and increases the computational time needed to solve the problem. By using the DEA methodology for solving the portfolio selection problem, a significant amount of data which has to be considered when making an investment decision was incorporated in order to produce portfolios that performed better than the market portfolio, thus showing that more efficient stocks do create portfolios with higher returns. The results of this study show that using data from financial reports decreases the risk of making investing 
mistakes by following the market movements induced by the irrational behavior of market stakeholders.

Moreover, the portfolios that were formed according to efficiency scores from models that are input oriented have been shown to be more conservative. On the other hand, the portfolios that were formed according to efficiency scores from output-oriented models have been shown to be generally more aggressive. It has also been shown that using efficiency scores to weight the portfolio has positive influence on return compared to equally structured, but equally weighted portfolio. This paper shows that including financial ratios does make a difference and improves the efficiency and successfulness of a portfolio selection strategy and, that paying attention solely to market data is inadequate. These results substantiate the importance of fundamental analysis showing the overall financial health of the stock issuer. The limitation of this paper is the relatively small number of analyzed stocks, due to the small liquidity of the stock market. Furthermore, popular market and financial measures were used but it has been shown that there exists a high correlation among some inputs and among some outputs. Some other combination of these measures might provide better portfolios. Moreover, the analysis was done without transaction costs, which can be very high on markets such as the Croatian capital market. Future research includes plans for sector differentiation of chosen stocks, which would enable incorporating limits on values of financial and market ratios, characteristic for that particular industry sector. The intention is also to do more research on the importance of using data from financial reports when making an investment decision.

\section{References}

[1] Artzner et al. (1999). Coherent measures of risk. Mathematical Finance, 9, 3 (July 1999), 203-228.

[2] Chen, H-H. (2008) Stock selection using data envelopment analysis. Industrial Management \& Data Systems, 108(9), 1255-1268. doi:10.1108/02635570810914928.

[3] Cooper, W., Seiford, L. M. and Zhu, J. (2011). Handbook on Data Envelopment Analysis. New York: Springer.

[4] Edirisinghe, N.C.P. and Zhang, X. (2007). Generalized DEA model of fundamental analysis and its application to portfolio optimization. Journal of Banking \& Finance 31, 3311-3335. doi:10.1016/j.jbankfin.2007.04.008.

[5] Gardijan, M. and Kojić, V. (2012). DEA-based investment strategy and its application in the Croatian stock market. Croatian Operational Research Review (CRORR), 3, 2012, 203-212.

[6] Klopp, G. A. (1985). The analysis of the efficiency of productive systems with multiple inputs and outputs. Ph.D. dissertation, University of Illinois, Chicago.

[7] Lim, S., Oh, K.W. and Zhu, J. (2013). Use of DEA cross-efficiency evaluation in portfolio selection: An application to Korean Stock Market. European Journal of Operational Research, 236, 1, 361-368. 
the Zagreb Stock Exchange

[8] Lopes, A., Edgar L., Marcus L. and da Costa, Jr., N., (2008). DEA investment strategy in the Brazilian stock market. Economics Bulletin, 13, 2, 1-10.

[9] Markowitz, H. (1952). Portfolio selection. The Journal of Finance, 7(1), 77-91.

[10] Neralić, L. (1992). Sensitivity analysis of the proportionate change of outputs or/and inputs of the additive model in Dana Envelopment Analysis, V. Bahovec, Lj. Martić, L. Neralić (ed.) Proceedings of the 2nd Conference on Operational Research KOI '92, Rovinj, Croatia, 71-80.

[11] Neralić, L. (1994). Sensitivity Analysis in Data Envelopment Analysis: A Review, V. Rupnik and M. Bogataj (eds.), Proceedings of the $2^{\text {nd }}$ Slovenian Symposium on Operations Research SOR'94, Portorož, 29-42.

[12] Neralić, L. (1996). O nekim primjenama analize omeđivanja podataka u bankarstvu. Ekonomija (On some applications of Data Envelopment Analysis in banking), 2(3), 493-521.

[13] Neralić, L. (2004a). Preservation of efficiency and inefficiency classification in data envelopment analysis. Mathematical Communications, 9 (2004), 51-62.

[14] Neralić, L. and Stein, O. (2004b). On regular and parametric data envelopment analysis. Mathematical Methods of Operations Research, No. 60, 15-28. doi:10.1007/s001860300338.

[15] Pätäri, E.J., Leivo, T. H. and Honkapuro, V.S. (2010). Enhancement of value portfolio performance using data envelopment analysis. Studies in Economics and Finance, 27(3), 223-246. doi:10.1108/10867371011060036.

[16] Powers, J. and McMullen P. (2002). Using Data Envelopment Analysis to select efficient large cap securities. Journal of Business and Management, 7(7), 31-42.

[17] Rabar, D. (2010). Ocjenjivanje efikasnosti poslovanja hrvatskih bolnica metodom analize omeđivanja podataka (Efficiency assessment of Croatian hospitals using Data Envelopment Analysis). Ekonomski pregled (Economic Review), 61 (9-10), 511-533.

[18] Šegota, A. (2008). Evaluating shops efficiency using Data Envelopment Analysis: Categorical approach. Zbornik radova Ekonomskog fakulteta u Rijeci (Proceedings of Rijeka Faculty of Economics), 26(2), 195-212.

[19] Škrinjarić, T. (2014). Investment strategy on the Zagreb Stock Exchange based on dynamic DEA. Croatian Economic Survey, 16, 129-160. doi:10.15179/ces.16.1.5.

[20] Škrinjarić, T. (2014). Ocjena učinkovitosti dioničkih fondova u Hrvatskoj primjenom analize omeđivanja podataka (Assessment of equity funds in croatia using Data Envelopment Analysis). Ekonomski vjesnik: časopis Ekonomskog fakulteta u Osijeku (Econviews: journal of Faculty of Economics in Osijek), XXVI, No. 1, 283-298.

[21] Song, I. (2014). New quantitative approaches to asset selection and portfolio construction. Submitted in partial fulfillment of the requirements for the degree of Doctor of Philosophy in the Graduate School of Arts and Sciences.

[22] Žager, K., Mamić Sačer, I., Sever, S. and Žager. L. (2008) Analiza financijskih izvještaja (Analysis of Financial Statement), Zagreb: Masmedia.

[23] Zamani, L., Beegam, R. and Borzoian, S. (2014). Portfolio selection using Data Envelopment Analysis (DEA): A case of select indian investment companies. International Journal of Current Research and Academic Review, 2, 4, 50-55. 